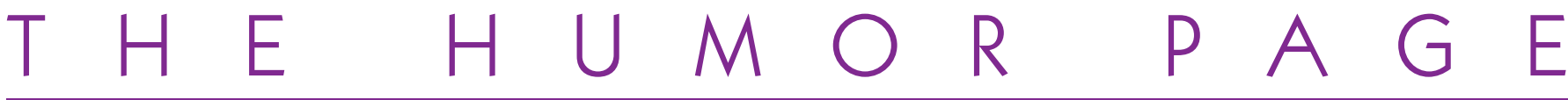

\section{Some thoughts on Evidence Based Dentistry after reading an article in the April Harvard Business Review}

\author{
Alain BENAUWT
}

It is not just us deep thinkers in our medical ivory tower who are pondering the analyses of numerical studies and how they can be put to practical use!

Here are a few quotations taken from the eminent economic journal cited in our title concerning the decision-making processes utilized by business managers.

- The notion that if you can't measure it, it doesn't count, is completely false!

- In order to take our measurements we use the model of rats looking for cheese in a maze...ls that a useful model for evaluating the way humans behave?

- We have to consider the possibility that what we cannot measure might be the most important aspect of the situation!

- There is certainly no doubt that qualitative factors are important and that paying too much attention to mathematical models can be dangerous.

I don't suggest that we denigrate the rare studies dealing with the criteria needed for EBD because these are studies that were difficult to carry out, that demanded great effort from their authors, and that have had an eminently respectable and enriching effect on our daily practice of orthodontics. I simply want to modify the way we utilize them by suggesting we choose the golden mean: these studies are irreplaceable, but they are valuable only under certain very precise conditions and are incapable of taking into account all the parameters associated with a complex relationship between individuals. Therefore we must be aware of them so we won't engage in outlandish ventures, but still, after mature reflection, not allow ourselves to become fettered by their conclusions.

These thoughts remind me of a story that André Santini, the mayor of Issy-les Moulineaux and a former federal minister, was fond of telling about Mr. Darty, the founder of a chain of stores. "When Darty's organization was in the process of determining where to locate a new store its team of expert accountants, architects, and businessmen carried out highly detailed planning

Address for correspondence:

A. BENAUWT,

21 , rue Hoche,

92130 Issy-les-Moulineaux.

a.benauwt@gmail.com 
studies. Then Mr. Darty would have his chauffeur drive him to the site where he would descend from his limousine and make an on foot tour of the location, finishing up by announcing, 'this spot was good or not so good or that other place was really better!' The decision was not made only by assessing the conclusions reached by the balance sheets of experts but also by Mr. Darty's instinctive flair!"

The danger we confront is allowing ourselves to engage in stereotypical behavior dictated by administrative hierarchies that by nature love the orderliness of numbers. That way we would sometimes wind up arriving at excessively rigid conclusions.

Here are two more quotations from the Harvard business journal about the way management runs hospitals in the United States:

- It takes 10 to 20 years for a new procedure to be accepted by most establishments

- There is a 55\% chance that patients will be treated in accordance with up-to-date scientific data...

Things cannot be any better in France! 